\title{
Comparação entre vazões estimadas e medidas: um estudo para a bacia hidrográfica do rio Branco/MT
}

A água é um recurso essencial à vida, utilizada para diversos fins, portanto, conhecer as condições hídricas de bacias hidrográficas é importante para o gerenciamento e planejamento dos recursos hídricos, propiciando (no que diz respeito) o desenvolvimento sustentável. Este trabalho tem como objetivo comparar dados de vazão da bacia hidrográfica do rio Branco, estimadas pelo sistema de outorga com a vazão medida in locu no mês de outubro. A bacia do rio Branco está localizada entre Barra do Bugres e Nova Olímpia, dois municípios em Mato Grosso que se destacam pela produção de cana-de-açúcar e pecuária de corte. Sendo assim, a bacia desempenha papel importante para os sistemas produtivos, quanto a irrigação e dessedentação dos animais. A medição de vazão no rio foi realizada pelo método flutuador em nove pontos da bacia, enquanto os valores estimados de vazão foram obtidos no Sistema Integrado de Monitoramento e Licenciamento Ambiental de Mato Grosso. Em seguida, os dados obtidos foram analisados estatisticamente pelos testes de normalidade e de Correlação de Spearman. Também foi realizada comparação entre as vazões nos pontos amostrados. Posteriormente, avaliou-se o desempenho do método de estimativa por meio dos coeficientes de correlação ' $r$ ', índice de concordância ' $d$ ' e índice de confiança ' $c$ '. Por fim, foi analisada a possibilidade de outorga na bacia. Os resultados demonstraram vazão inferior para as nascentes (P7, P8 e P9), enquanto os demais pontos apresentaram maior disponibilidade de água, obedecendo a ordem do desague dos afluentes. A análise comparativa demonstrou diferenças entre a vazão estimada e a vazão medida in locu em todos os pontos estudados. O teste de Correlação de Spearman demonstrou não haver correlação entre as vazões. A avaliação de desempenho do método de estimativa revelou baixa confiabilidade, exatidão e precisão, ressaltando a fragilidade do sistema. Conclui-se também que a bacia hidrográfica do rio Branco necessita de pedido de outorga em todos os pontos estudados, possibilitando melhor gestão e planejamento dos usos dos recursos naturais da bacia.

Palavras-chave: Gestão de Recursos Hídricos; Método Flutuador; Vazão de Referência; Outorga.

\section{Comparison between estimated flows and measures: a study for the hydrographic basin of Branco River/MT} \begin{abstract}
Water is an essential resource for life, used for various purposes, so knowing the water conditions of watersheds is important for the management and planning of water resources, providing (as regards) sustainable development. This paper aims to compare the flow data of the Rio Branco watershed, estimated by the grant system with the flow measured in locu in October. The Branco River basin is located between Barra do Bugres and Nova Olímpia, two municipalities in Mato Grosso that stand out for their sugarcane and beef cattle production. Thus, the basin
plays an important role for the production systems, regarding the irrigation and desedentation of the animals. River flow measurement was performed by the float method in nine points of the basin, while the estimated flow values were obtained from the Mato Grosso Integrated Environmental Monitoring and Licensing System. Then, the obtained data were statistically analyzed by Spearman's normality and correlation tests. A comparison was also made between the flows at the sampled points. Subsequently, the performance of the estimation method was evaluated using correlation coefficients ' $r$ ', agreement index ' $d$ ' and confidence index ' $c$ '. Finally, the possibility of granting in the basin was analyzed. The results showed lower flow to the springs (P7, P8 and P9), while the other points presented higher water availability, obeying the order of the flow of the tributaries. The comparative analysis showed differences between the estimated flow and the masured flow in locu in all studied points. Spe rmion method revealed low reliability, accuracy and precision, highlighting the fragility of the system. It is also concluded that the Branco river basin needs a grant request in all studied points, enabling better management and planning of the natural resources uses of the basin.
\end{abstract}

Keywords: Water Resources Management; Float Method; Reference Flow; Granting.

Topic: Engenharia de Recursos Hídricos

Reviewed anonymously in the process of blind peer.
Received: 10/02/2018

Approved: 24/03/2018

Jessica Ramos de Oliveira (iD

Universidade do Estado de Mato Grosso, Brasil

http://lattes.cnpq.br/5961662650816768

http://orcid.org/0000-0003-1450-3859

jessica-r24@hotmail.com

Tiago Maboni Derlan (D)

Universidade do Estado de Mato Grosso, Brasil

http://lattes.cnpq.br/6557546092273236

http://orcid.org/0000-0003-1661-4843

tiago_mabonid@hotmail.com

Tadeu Miranda de Queiroz

Universidade do Estado de Mato Grosso, Brasil

http://lattes.cnpq.br/2582121765769124

http://orcid.org/0000-0002-1959-7658

tdmqueiroz@yahoo.com.br

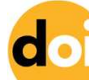

DOI: 10.6008/CBPC2179-6858.2018.003.0012
Referencing this:

OLIVEIRA, J. R.; DERLAN, T. M.; QUIEROZ, T. M.. Comparação entre vazões estimadas e medidas: um estudo para a bacia hidrográfica do rio Branco/MT. Revista Ibero Americana de Ciências Ambientais, v.9, n.3, p.136-148, 2018. DOI: http://doi.org/10.6008/CBPC21796858.2018.003.0012 


\section{INTRODUÇÃO}

A água é um recurso natural indispensável para a sobrevivência do homem e para os demais seres vivos do Planeta. Solvente universal da biosfera, assume papel fundamental na absorção de nutrientes do solo pelas plantas, na composição do clima das regiões, principalmente por constituir aproximadamente três quartos dos seres vivos (PAZ et al., 2000).

Fundamental para a manutenção da vida nas cidades, indispensável para as indústrias e principal determinante da produtividade das zonas rurais, é disponibilizada para o abastecimento público, industrial, agrícola dentre outras utilidades, proporcionando o crescimento da economia e manutenção da vida de modo geral. Dentre os principais setores utilizadores deste recurso natural em todo o globo, destaca-se o volume consumido em sistemas de irrigação, que no Brasil representam $67 \%$ de toda a água consumida, como apresenta ANA (2017).

Os rios representam a principal fonte de água doce para suprir as necessidades e atividades econômicas do homem, fornecendo suporte ao desenvolvimento urbano, a saúde, agricultura, educação ambiental e outras áreas sociais, culturais e ambientais, objetivando o crescimento sustentável (ALVES et al., 2009). Conhecer parâmetros e características hidrológicas, como a vazão dos rios, é essencial para auxiliar a sociedade e os gestores no planejamento das atividades econômicas locais e regionais (PINHEIRO et al., 2014).

Entretanto, Coaguila et al. (2015) coloca em questão a utilização de água em bacias hidrográficas frágeis. Preocupado com a escassez, os autores afirmam ser de extrema importância realizar avaliações técnicas que possam gerar informações para contribuir para o uso adequado da água, principalmente em períodos com taxas de precipitação reduzidas. Afirmam também que estes estudos podem ser realizados através de fatores como a vazão e produtividade de água pela bacia. Lira et al. (2013) também ressaltam a preocupação com a disponibilidade contínua do recurso hídrico possibilitado pela gestão da produtividade versus utilização.

No Brasil, a gestão dos recursos hídricos passou a ser regulamentada em 8 de janeiro de 1997, por meio da Lei no 9.433 implementando desde então, um sistema de outorgas para liberação do uso da água. De acordo com o artigo $17^{\circ}$ do decreto citado, a disponibilidade hídrica deve ser estabelecida em função de características hidrológicas da bacia sobre a qual incide a outorga. Para gerenciar o uso dos recursos hídricos de forma integrada e descentralizada com a participação da sociedade foram também criados Comitês de Bacias Hidrográficas ( $\mathrm{CBH})$. Os $\mathrm{CBH}$ promovem debates de questões relacionadas aos recursos hídricos; tratam de assuntos de conflitos entre usuários; estabelecem critérios de uso e promoção da harmonização do uso competitivo do recurso natural da bacia hidrográfica (ALVES et al., 2009).

Para a gestão eficiente das bacias hidrográficas é fundamental conhecer os dados de variáveis hidrológicas que auxiliam nas sugestões de impactos ao meio ambiente, como afirmam Bonifácio et al. (2013). De acordo com os autores, tais dados auxiliam na estimativa de volume de água para abastecimento 
humano, na previsão e prevenção de inundações e enchentes e no cálculo da vazão mínima em uma bacia sem que haja prejuízo ecológico.

No Mato Grosso o órgão gestor dos recursos hídricos é a Secretária de Estado do Meio Ambiente SEMA, contudo cabe ao Conselho Estadual de Recursos Hídricos de Mato Grosso (CEHIDRO) as funções deliberativas, normativas e consultivas referentes à política de recursos hídricos do Estado. Dentre suas competências, definidas pelo art. $1^{\circ}$ do Decreto N. 3.952/2002, está a deliberação sobre os critérios e normas para outorga.

A análise de pedidos de outorga de captação superficial de água no Mato Grosso segue os critérios estabelecidos na Resolução CEHIDRO no 27 de 9 de julho de 2009, que considera o somatório de vazões em um curso d'água que podem ser outorgadas, como também a definição dos usos insignificantes, utilizando como vazão de referência a Q95 (permanência de uma determinada vazão por 95\% do tempo no ano). Dessa maneira, a vazão máxima que pode ser outorgada para usos consuntivos é de $70 \%$ da Q95, já para usos individuais é estipulado o valor de $20 \%$ da Q95, contudo este valor pode ser excedido para utilização no consumo humano e na dessedentação de animais. Quanto a definição de usos insignificantes, a normativa estabelece para cursos d'água com vazão de referência de até $200 \mathrm{~L} \cdot \mathrm{s}^{-1}\left(0,2 \mathrm{~m}^{3} \cdot \mathrm{s}^{-1}\right)$ uso de $0,25 \%$ da Q95 como captação insignificante. Já em cursos d'água com vazão de referência superior a $200 \mathrm{~L} . \mathrm{s}^{-1} \mathrm{o}$ uso de até $5 \mathrm{~L} . \mathrm{s}^{-1}$ $\left(0,0005 \mathrm{~m}^{3} \cdot \mathrm{s}^{-1}\right)$ é considerado insignificante, contudo, bacias hidrográficas que atingirem somatório de captações insignificantes superior a $20 \%$ da vazão de referência deixarão de considerar o conceito de insignificante devendo solicitar outorga.

A SEMA fornece ao público a consulta a diversos dados por meio do Sistema Integrado de Monitoramento e Licenciamento Ambiental (SIMLAM), que une metodologias e ferramentas a fim de auxiliar a gestão do meio ambiente no Estado. $\mathrm{O}$ site fornece informações relacionadas a licenças e autorizações de retirada, mapas, cadastros de pesca, outorga, entre outros.

De acordo com a Agência de Proteção Ambiental Norte Americana (United States Environmental Protection Agency - EPA) (1997), a vazão de um rio ou córrego é afetado diretamente pelo clima, aumentando em épocas chuvosas e diminuindo em tempos de estiagem. Dessa forma o volume de fluxo dos rios é alterado ao longo das estações do ano, sendo menor quando as taxas de evapotranspiração são maiores (PALHARES et al., 2007).

Durante o período de seca Dallacort et al. (2011), cita os meses de junho, julho e agosto como períodos críticos, já que segundo ele, nesse período praticamente não há ocorrência de chuvas em Tangará da Serra, município próximo à região do estudo, com média de precipitação de apenas 14,56 mm. Para Fenner et al. (2014), o mês de setembro apresenta média de 2,3 mm de armazenamento de água no solo, o menor índice em todo ano, resultado da ausência de chuvas como citado por Dallacort et al. (2011), afetando diretamente o volume dos rios na região, em conformidade com apresentado por EPA (1997). Estudos de Fenner et al. (2014) e Souza et al. (2013) evidenciam que os meses de maio a outubro apresentam um déficit hídrico crítico que chega até $-111,3 \mathrm{~mm}$, sendo suprido logo após às primeiras chuvas que ocorrem em meados de outubro, acompanhando as estações como afirmado por Palhares et al. (2007). 
Nesse contexto, evidencia-se a importância, sobretudo, de conhecer o comportamento das vazões dos rios, principalmente durante os períodos mais críticos da seca, buscando garantir o mínimo de recurso para a manutenção das atividades na bacia hidrográfica possibilitando avaliar o estado de disponibilidade de água para o uso comum. Sendo assim, o obtivo do estudo foi comparar as vazões medidas in loco em diferentes pontos distribuídos na bacia hidrográfica do rio Branco com as vazões de referência estimadas pelo sistema SIMLAM, a fim de identificar variações críticas entre os dados, possibilitando discussões acerca das vazões outorgáveis para a bacia.

\section{MATERIAIS E MÉTODOS}

\section{Caracterização da área de estudo}

A área de estudo é a Bacia Hidrográfica do Rio Branco, localizada nos municípios de Barra do Bugres e Nova Olímpia em Mato Grosso, inseridos na mesorregião sudoeste do estado, caracterizada por um clima tropical quente e subsumido, contendo duas estações bem definidas, uma estação seca nos meses de maio a setembro e outra chuvosa nos meses de outubro a abril (DALLACORT et al., 2011). A Bacia Hidrográfica do Rio Branco, bem como sua localização e pontos de medição e estimativa estão ilustrados na Figura 1.

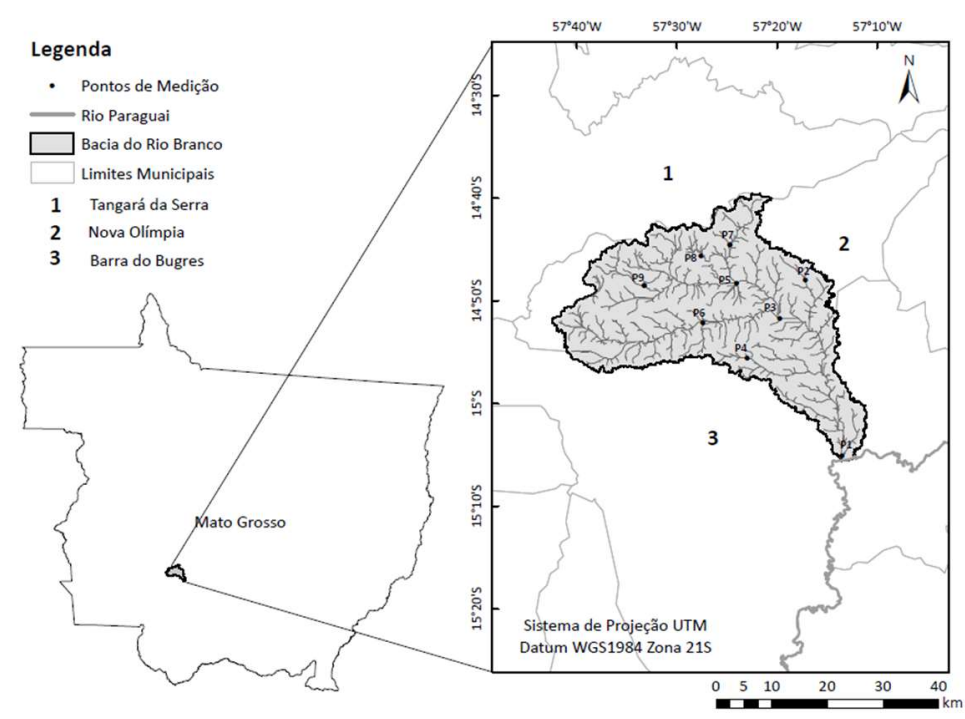

Figura 1: Localização da bacia hidrográfica do Rio Branco.

A Bacia Hidrográfica do Rio Branco possui área total de $1.285,42 \mathrm{~km}^{2}$, delimitada por um perímetro de $332,84 \mathrm{~km}$. A declividade média da bacia é de 2,14\%, contendo densidade de drenagem de 1,25 km/km² (OLIVEIRA et al., 2017). O rio Branco é um afluente da margem direita do rio Paraguai, um dos formadores do Pantanal e da Bacia Platina o que destaca sua importância e fornece a relevância para esse trabalho.

Através das visitas a campo foi possível observar a predominância da atividade agrícola, caracterizada pelo monocultivo de cana-de-açúcar e pecuária de corte, nos arredores dos canais fluviais da bacia. De acordo com a ANA (2017), a área de cana-de-açúcar irrigada em Barra do Bugres e Nova Olímpia chega a 30\% do total de área plantada. A Agência ainda ressalta as dificuldades para identificar as fontes de 
água utilizada nestas irrigações, haja vista a grande mobilidade e variedade dos equipamentos, gerando variação significativa no balanço hídrico a cada safra, o que pode resultar em alteração do fluxo natural dos cursos d'água. As medições de velocidade e vazão foram realizadas em nove pontos distribuídos no interior da bacia, compreendendo nascentes, no curso principal, intermediário e no exutório (Figura 1).

\section{Medição de vazão}

A medição de vazão foi realizada no mês de outubro de 2017, para tanto foi utilizado o método simples de medição indireta de vazão, o método por flutuador, caracterizado por Carvalho (2008) como um método manual e simples de medição de vazão, em que exige um embasamento teórico para sua aplicação. Para medição direta da vazão foram observadas as recomendações de Santos et al. (2001) e Palhares et al. (2007), escolhendo no rio, em cada ponto de medição, um trecho retilíneo, ausente de obstáculos no fundo e com boas condições de velocidade, priorizando locais sem variações bruscas, evitando-se águas paradas.

Santos et al. (2001) ressalta a necessidade da definição de algumas grandezas características do escoamento para a medição direta de vazão, são elas as grandezas geométricas, que envolvem área, profundidade, largura, entre outros, e as grandezas referentes ao escoamento, envolvendo velocidade e vazão. As grandezas geométricas foram obtidas por meio de etapas, iniciando com o estabelecimento de três seções transversais com cinco metros de distância entre as mesmas, em seguida medindo-se a largura de cada seção por meio de um bastão de madeira com uma trena acoplada. Posteriormente foram medidas as profundidades das seções, obtidas a cada 0,5 m de distância uma da outra. Para o cálculo da área de cada ponto, calculou-se a média das medidas de profundidade e a média das medidas de largura, os resultados das médias foram multiplicados, entre si, obtendo-se a área molhada em metros quadrados.

A velocidade média da corrente foi obtida por meio de um flutuador. EPA (1997) afirma que um bom objeto para usar como flutuador deve ter flutuabilidade suficiente para permanecer logo abaixo da superfície da água, de maneira que nessa posição a velocidade máxima normalmente ocorre. Portanto, utilizou-se uma garrafa plástica de $500 \mathrm{ml}$ contendo $300 \mathrm{ml}$ de água e nos cursos d'água rasos, em que não era possível o uso da garrafa, foi utilizado um objeto flutuante de superfície. O flutuador foi lançado no rio, e cronometrado o tempo gasto para percorrer a distância de $10 \mathrm{~m}$, determinada pelas seções transversais. Este procedimento foi repetido cinco vezes para obter um valor médio.

A velocidade média do fluxo de água é dada pelo quociente da distância entre as seções e o tempo gasto. As medições de velocidade de um fluxo superficial devem ser corrigidas, pois estas podem ser superestimadas (MOSLEY et al., 1993, citado por ALVARENGA et al., 2012). Netto et al. (1998) indicam que seja utilizado um coeficiente de correção na velocidade média, de 0,80 a 0,90 . Utilizou-se do valor de 0,85 obtendo-se a velocidade média corrigida nos pontos em que foi utilizado um flutuador superficial. Por meio dos dados da caracterização morfológica e velocidade média do curso d'água de cada ponto foi possível determinar a vazão obtida pelo produto da velocidade média pela área molhada. 


\section{Pedido de outorga de água no Rio Branco}

Baseando-se nos instrumentos legais vigentes, foi comparado os dados referentes a vazão de referência do mês de outubro fornecida pela SEMA por meio do Sistema Integrado de Monitoramento e Licenciamento Ambiental de Mato Grosso (SIMLAM - MT) com a vazão medida in locu no mesmo período. Posteriormente, foi analisada a possibilidade de outorga do uso da água em cada um dos pontos.

\section{Análise estatística para comparação}

Após a coleta de dados, foi realizada a análise estatística por meio do software RStudio.Version (1.0.143) realizando-se o teste de normalidade de Shapiro-Wilk, com 95\% de significância, o qual demonstrou uma distribuição não normal dos dados. Assim sendo, aplicou-se o teste de Correlação de Spearman, a fim de verificar a correlação entre os dados estimados e os dados medidos in locu.

Para a avaliação estatística do desempenho do método de estimativa de vazão foi correlacionado os valores estimados com os valores medidos, utilizando-se de indicadores estatísticos, sendo eles a precisão (coeficiente de correlação de Spearman ' $r$ '), a exatidão (índice de Willmott ' $d$ ') e a confiança ou desempenho (índice 'c'). A precisão ' $r$ ' é obtida através do coeficiente de correlação, o qual indica o grau de dispersão dos dados com relação à média (LEITÃo et al., 2007). A exatidão 'd' proposta por Willmott et al. (1985), relacionase com a distância entre os valores observados e os valores estimados, resultado em valores com variação de 0 (nenhuma concordância) a 1 (concordância perfeita), este é obtido através da Equação 1.

$$
d=1-\left[\frac{\sum(P i-O i)^{2}}{\sum(|P i-O|+|O i-O|)^{2}}\right]
$$

Sendo, Pi o valor estimado, Oi o valor observado e O a média dos valores observados.

A confiança ou desempenho ' $c$ ' proposta por Camargo et al. (1997), que representa o desempenho e confiança do método, é dada pelo produto dos índices de precisão ' $r$ ' e de exatidão 'd', cujo resultado é interpretado por meio de uma classificação do desempenho do método empregado, conforme apresentado pelo Quadro 1.

Quadro 1: Categorias de classificação do índice de Desempenho de Camargo et al. (1997).

\begin{tabular}{|l|l|}
\hline Valor de "c" & Desempenho \\
\hline$>0,85$ & Ótimo \\
\hline 0,76 a 0,85 & Muito Bom \\
\hline 0,66 a 0,75 & Bom \\
\hline 0,61 a 0,65 & Mediano \\
\hline 0,51 a 0,60 & Sofrível \\
\hline 0,41 a 0,50 & Mau \\
\hline$<0,40$ & Péssimo \\
\hline
\end{tabular}

\section{RESULTADOS E DISCUSSÃO}

Os resultados da caracterização geométrica e do escoamento dos pontos estudados na Bacia Hidrográfica do Rio Branco são apresentados na Tabela 1. De acordo com os dados, os pontos P7, P8 e P9 apresentaram menor vazão em comparação com os demais pontos estudados. Este fato é justificado pelos 
pontos serem caracterizados como riachos de cabeceira, como pode ser observado na Figura 1, com área de pastagem predominante. Contudo, o ponto P8 apresentou vazão maior que os pontos P7 e P9 o que se justifica pelo ponto P7 conter uma captação de água para formação de lagoa em uma propriedade privada destinada a dessedentação dos animais, como observado na visita de campo. O ponto P9 também é destinado a dessedentação dos animais, contudo não possui encanamentos para captação, portanto apresenta pequena extensão de área de reserva com vegetação espaçada, provavelmente justificada pela presença do gado. Deste modo, pode-se supor que as atividades antrópicas na bacia hidrográfica do rio Branco podem associar-se a diminuição de vazão da água e em casos extremos pode gerar a intermitência em período de estiagem ou até desaparecimento de cursos d'água, interferindo no fluxo normal de escoamento e nos usos múltiplos dos recursos desta bacia. Horikoshi et al. (2007) destacam que o balanço hídrico de uma região se mantém sem fortes alterações naturais, contudo com aumento populacional e uso inconsciente da água, a ação antrópica pode interferir no ciclo hidrológico.

Tabela 1: Caracterização geométrica e do escoamento dos pontos em estudo.

\begin{tabular}{|l|l|l|l|}
\hline Pontos de coleta & Área molhada de escoamento $\left(\mathbf{m}^{\mathbf{2}}\right)$ & Velocidade média de escoamento $\left(\mathbf{m}^{\left.-\mathbf{s}^{-1}\right)}\right.$ & Vazão $\left(\mathbf{m}^{\mathbf{3}} \cdot \mathbf{s}^{\mathbf{1}}\right)$ \\
\hline P1 & 15,57 & 0,42 & 6,54 \\
\hline P2 & 1,88 & 2,18 & 4,10 \\
\hline P3 & 5,60 & 1,17 & 6,58 \\
\hline P4 & 8,88 & 0,71 & 6,35 \\
\hline P5 & 6,32 & 0,24 & 1,51 \\
\hline P6 & 0,18 & 1,67 \\
\hline P7 & 1,32 & 1,05 & 0,04 \\
\hline P8 & 0,04 & 0,05 & 0,11 \\
\hline P9 & 2,10 & & 0,01 \\
\hline
\end{tabular}

O ponto P2 também é uma nascente (Figura 1), no entanto, apresentou vazão superior aos pontos P7, P8 e P9, o que pode estar associado com a proximidade deste curso d'água com o município de Nova Olímpia, podendo ser uma fonte de despejo de resíduos urbanos, aumentando assim a vazão neste ponto. Pode associar-se também ao fato dos pontos P7, P8 e P9 possuírem em seus arredores, áreas de pastagem, nas quais a água é destinada a dessedentação de animais, podendo reduzir a vazão, gerando também efeito de pisoteio, com consequente reflexo na compactação do solo reduzindo a infiltração de água e o armazenamento do solo. Diversos autores destacam a compactação do solo, vegetação raleada, a redução da fertilidade do solo e erosão como consequências da presença de gado em bacias hidrográficas (MENEZES et al., 2009; PINTO et al., 2005; FARIA et al., 2003). Nos arredores do ponto P2 predominam o cultivo de canade-açúcar com colheita mecanizada. De acordo com Martins Filho et al. (2009), a colheita mecanizada promove a cobertura do solo com os resíduos da cultura, melhorando a estruturação do solo e a sua permeabilidade, gerando aumento da infiltração de água e armazenamento, fato comprovado pelo estudo de Marouelli et al. (2010) destacando a economia de água por conta da utilização de palhada no cultivo de repolho. Sendo assim, pode-se supor que a palhada do cultivo de cana-de-açúcar próximo ao ponto P2 pode gerar a redução do uso da água do rio Branco para a irrigação. Destaca-se também que na região próxima ao ponto P2 parte da irrigação é realizada com a vinhaça, um subproduto do processo sucroalcooleiro, o que reduz a utilização dos corpos hídricos para irrigação, provavelmente contribuindo para a maior vazão hídrica 
neste ponto. Bonini et al. (2014) ressaltou positivamente o uso de vinhaça nos cultivos de cana-de-açúcar como uma alternativa sustentável, que permite que a água potável seja poupada para outros fins mais exigentes, contribuindo também para a conservação dos recursos hídricos.

O ponto P5 refere-se à confluência dos cursos d'água localizados os pontos P7, P8 e P9 (Figura 1), apresentando assim vazão superior ao obtido com o somatório das vazões dos três pontos, já o ponto P3 refere-se à confluência dos cursos d'água onde estão localizados os pontos P6 e P5, apresentando vazão maior que o somatório dos dois pontos. Isto ocorre por gerar maior escoamento d'água devido a união dos cursos d'água, ocasionando em aumentos na vazão. Contudo, observou-se que o ponto P4 apresentou vazão próxima da obtida no ponto $\mathrm{P3}$, apesar deste ponto referir-se a uma área de escoamento superior, este fato justifica-se pelo ponto P4 conter uma área alagada muito extensa seguida de uma estrada. Nesse local o represamento do rio desviou seu curso original, o qual foi dividido por duas manilhas que distribuem a vazão entre a vegetação formando uma grande área alagada, descaracterizando o rio. Dessa forma, provavelmente, grande parte do volume de água pode ser absorvido pelas plantas e pela própria permeabilidade do solo e até mesmo evaporado, o que pode justificar a redução da vazão.

O ponto P1 está localizado próximo a foz do rio Branco (Figura 1), concentrando assim todo o escoamento dos seus diversos cursos d'água, sendo assim espera-se que o exutório apresente maior vazão que demais pontos localizados na bacia hidrográfica. De acordo com a Tabela 1 o ponto P1 apresentou vazão ligeiramente menor que a vazão do ponto P3, contudo a vazão obtida na foz deveria refletir no mínimo o somatório das vazões de seus afluentes, os pontos P2, P3 e P4, no entanto a vazão foi muito inferior. Este fato pode ser justificado pela presença de empreendimentos agropecuários e agroindustriais, entre outros, na bacia, que provavelmente utilizam a água do rio Branco em suas atividades, diminuindo assim a vazão no exutório.

Pesquisa realizada no Diário Oficial do Estado revelou apenas uma outorga de captação entre os pontos P1 e a confluência dos pontos P2, P3 e P4. A outorga de captação está vencida desde 2016, a qual possuía uma vazão outorgada no mês de outubro de $0,4722 \mathrm{~m}^{3} \cdot \mathrm{s}^{-1}$, contudo pelo fato de estar vencida a mesma foi desconsiderada neste estudo.

Analisando as vazões medidas no curso baixo do rio, considerando o exutório (P1) e os três principais tributários à montante (P2, P3 e P4), contabiliza-se uma diferença de menos $10,49 \mathrm{~m}^{3} . \mathrm{s}^{-1}$ na vazão esperada para o ponto $\mathrm{P} 1$, a qual deveria apresentar vazão mínima de $17,03 \mathrm{~m}^{3} \cdot \mathrm{s}^{-1}$, porém aferiu-se naquele ponto apenas $6,54 \mathrm{~m}^{3} \cdot \mathrm{s}^{-1}$. Ressalta-se ainda, que mesmo considerando a outorga já vencida, sua vazão de captação não seria suficiente para justificar sozinha tal diminuição. Esse resultado evidencia a existência de captações não registradas contribuindo para a diminuição da vazão no ponto P1, como reportado por Rebouças (2001), o qual chama atenção para a captação de água excessiva em bacias hidrográficas podendo gerar a redução do fluxo de escoamento dos rios, provocando sérias consequências sociais, ambientais e econômicas.

Observando as vazões estimadas pelo sistema verificou-se coerência, pois a vazão no ponto P1 é ligeiramente maior do que o somatório das vazões dos pontos P2, P3 e P4, o que é esperado. Cabe ressaltar que a estimativa não considera captações existentes ao longo do ponto avaliado e reflete uma expectativa 
de vazão baseado em dados históricos. Este resultado evidencia divergência entre a vazão estimada e a vazão medida apontando para possíveis falhas na outorga de água baseada na estimativa.

\section{Análise de comparação entre vazão estimada pelo sistema de outorga e medições in locu}

Através dos dados obtidos na consulta ao SIMLAM-MT e das medições de vazão realizadas no rio Branco foi possível estabelecer uma comparação entre as medições in locu e as vazões de referência estimadas pelo sistema, como demonstrado na Figura 2. Por meio da comparação foi possível observar variações entre os valores das vazões fornecidas pelo SIMLAM e os valores de vazões obtidas nas medições no rio Branco, as quais ocorreram por conta dos dados fornecidos pelo sistema se referirem apenas a uma estimativa, que pode estar sujeita a falhas. Observou-se que os pontos P2 e P4 apresentaram uma vazão de referência inferior ao valor da vazão medida in locu, esta diferença pode estar associada ao possível uso da água nas proximidades destes pontos, diminuindo assim a vazão na foz.

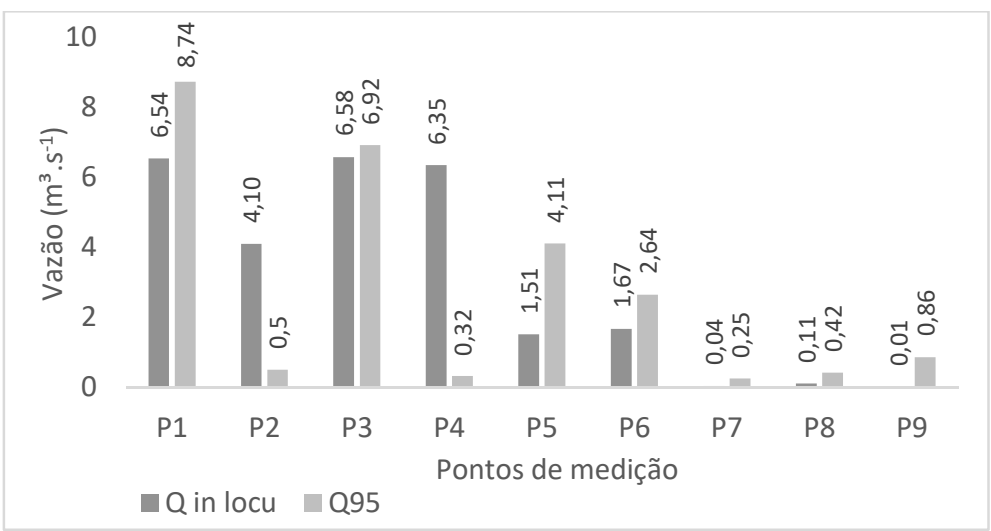

Figura 2: Comparação das vazões de referência estimadas pelo sistema SIMLAM (Q95) e das medições in locu ( $Q_{\text {mínima }}$ ).

Por meio da análise estatística verificou-se que não há correlação entre os dados, haja vista o teste ter apresentado o p-valor de 0,1618, demonstrando ausência de correlação estatística significativa. Este fato também é comprovado pelo valor do $r$ de 0,5167 . Sendo assim, pode-se compreender que os dados de vazão estimados pelo sistema não se aproximam da realidade, comprovando a fragilidade de sistemas de estimativas de vazão no gerenciamento de recursos hídricos.

O coeficiente de correlação ' $r$ ' apresentou uma precisão baixa, com valor de 0,52 , demonstrando o grau elevado de dispersão dos dados em relação à média evidenciando a fragilidade do método de estimativa de vazão. $O$ índice de exatidão ' $d$ ' apresentou valor de 0,78 , demonstrando baixa concordância entre os dados, haja vista a maior distância entre os dados de vazão medidos in locu e estimadas pelo sistema. 0 resultado do índice de confiança, conforme o critério proposto por Camargo et al. (1997) pode ser considerado como um mau desempenho, haja vista ter apresentado o valor de 0,45 . Portanto, a avaliação estatística do desempenho do método de estimativa indica baixa precisão, exatidão e confiança, demonstrando haver pouca concordância entre os valores de vazão estimada com a vazão medida in locu. Resultado semelhante foi obtido no estudo de Fioreze et al. (2008), em que foi verificado péssimo 
desempenho do método de equações de regionalização de vazão máxima e mínima na bacia hidrográfica do Ribeirão Santa Bárbara, em Goiás, de acordo com coeficientes de exatidão, precisão e confiança.

\section{Pedido de outorga de captação da água do rio Branco}

Na Tabela 2 são apresentados os valores das vazões medidas no rio Branco no mês de outubro e das vazões de referência do mês de outubro e seus respectivos limites para concessão de uso coletivo e uso individual.

Tabela 2: Dados das vazões de referência a vazão disponível outorgável e área de drenagem estimadas pelo sistema, e das medições in locu.

\begin{tabular}{|c|c|c|c|c|}
\hline $\begin{array}{l}\text { Pontos de } \\
\text { coleta }\end{array}$ & $\begin{array}{l}\text { Vazão in locu } \\
\left(\mathrm{m}^{3} \cdot \mathrm{s}^{-1}\right)\end{array}$ & $\begin{array}{l}\text { Vazão de referência Q95 } \\
\left(\mathrm{m}^{3} . \mathrm{s}^{-1}\right)\end{array}$ & $\begin{array}{l}\text { Vazão outorgável }- \text { uso } \\
\text { coletivo }\left(\mathrm{m}^{3} \cdot \mathrm{s}^{-1}\right)\end{array}$ & $\begin{array}{l}\text { Vazão outorgável }- \text { uso } \\
\text { individual }\left(\mathrm{m}^{3} \cdot \mathrm{s}^{-1}\right)\end{array}$ \\
\hline P1 & 6,54 & 8,74 & 5,64 & 1,74 \\
\hline $\mathrm{P} 2$ & 5,11 & 0,50 & 0,35 & 0,10 \\
\hline P3 & 6,58 & 6,92 & 4,84 & 1,38 \\
\hline P4 & 6,35 & 0,32 & 0,22 & 0,06 \\
\hline P5 & 1,51 & 4,11 & 2,88 & 0,82 \\
\hline P6 & 1,67 & 2,64 & 1,85 & 0,53 \\
\hline P7 & 0,04 & 0,25 & 0,18 & 0,05 \\
\hline P8 & 0,11 & 0,42 & 0,29 & 0,08 \\
\hline P9 & 0,01 & 0,86 & 0,60 & 0,17 \\
\hline
\end{tabular}

Conforme a Tabela 2, pode notar que os pontos P5, P6, P7, P8 e P9 apresentaram vazão outorgável de uso coletivo superior a vazão medida in locu, demonstrando a fragilidade da estimativa, principalmente em pequenos cursos d'água. As diferenças observadas podem representar um impacto ambiental sério, podendo provocar a intermitência momentânea ou prolongada de alguns cursos d'água por meio da captação acima do potencial hídrico. Larned et al. (2010) alertam sobre o risco de aumento e geração de rios temporários no próximo século devido a captação da água para usos socioeconômicos. Caso semelhante ocorreu na bacia do riacho Queima Pé, em Tangará da Serra, MT, utilizada para o abastecimento público quando, no ano de 2016 ocorreu grande crise hídrica, causando a proibição da captação de água do riacho, a fim de manter o recurso para uso de abastecimento da cidade. Contudo, os estudos de Gouveia et al. (2015) e Pessoa et al. (2012) alertavam sobre as fragilidades ambientais na bacia do riacho Queima Pé ocasionadas pelo uso e ocupação da terra predominantemente agropastoril e urbano.

Os valores de vazão estipulados pelo sistema como limite para o uso individual na bacia do rio Branco foram considerados relativamente baixos (variação de 0,05 a $1,74 \mathrm{~m}^{3} \cdot \mathrm{s}^{-1}$ ), demonstrando que a bacia possui um baixo potencial para exploração dos seus recursos hídricos. Contudo, observa-se que mesmo com vazões relativamente baixas para uso individual, todos os pontos estudados apresentaram vazões superiores ao considerado como insignificante pela CEHIDRO $\left(0,0005 \mathrm{~m}^{3} \cdot \mathrm{s}^{-1}\right)$, gerando a necessidade de pedido de outorga para captação da água nos pontos estudados na bacia do rio Branco, e nas quantidades citadas. Resultado semelhante foi obtido por Souza et al. (2012) que estudaram o Córrego da Capetinga no Distrito Federal e observaram a baixa potencialidade do córrego para a exploração de recursos hídricos e a dependência de pedido de outorga para captação da água. 


\section{CONCLUSÕES}

Por meio da medição de vazão na bacia hidrográfica do rio Branco notou-se que há um aumento gradativo da vazão do curso d'água principal entre a nascente e o exutório, o qual pode ser um indicativo de preservação ambiental do recurso hídrico na bacia do Rio Branco, como reflexo do baixo uso consuntivo de água pelas atividades agroindustriais presentes, embora tenha sido aferido um déficit de $10,49 \mathrm{~m}^{3} \cdot \mathrm{s}^{-1}$ entre o exutório (P1) e os 3 principais afluentes a montante (P2, P3 e P4).

Observou-se diferenças entre as vazões de referência (Q95) estimadas e as vazões obtidas por medição in locu em todos os pontos estudados, contudo esta diferença se deu pelo sistema basear-se apenas em uma estimativa, evidenciando as fragilidades do sistema. Por meio da análise estatística, verificou-se a ausência de correlação entre os dados, evidenciando a distinção entre os dados de vazão fornecidos pelo sistema e a vazão real do rio. A avaliação de desempenho do método de estimativa de vazão demonstrou baixa confiabilidade, precisão e exatidão quando comparado aos dados medidos in locu.

A bacia possui baixa potencialidade de exploração de seus recursos hídricos, considerando-se o valor relativamente baixo das vazões de uso individual. Contudo, conforme a legislação vigente em todos os pontos estudados é necessária o pedido de outorga para o uso da água, haja vista ultrapassarem o limite definido para usos insignificantes.

O estudo demonstrou as possíveis fragilidades das estimativas de vazão, no entanto é uma ferramenta de grande valia para os produtores e técnicos da área ambiental e de outorgas, pois proporciona a redução de tempo e dinheiro na determinação da Q95, permitindo também a determinação em locais onde não há monitoramento serial da vazão. Os conflitos pelo uso da água são evidentes, demonstrando a necessidade de investimentos em pesquisas que propiciem o monitoramento de vazão em um maior número de bacias hidrográficas, principalmente as micro e pequenas bacias hidrográficas.

AGRADECIMENTOS: Agradecemos à Fundação de Apoio à Pesquisa do Estado de Mato Grosso (FAPEMAT) pela concessão da bolsa de mestrado a um dos autores.

\section{REFERÊNCIAS}

ANA. Agência Nacional de Águas. Atlas irrigação: uso da água na agricultura irrigada. Brasília: ANA, 2017.

ALVARENGA, L. A.; MARTINS, M. P. P.; CUARTAS, L. A.; PENTEADO, V. A.; ANDRADE, A.. Estudo da qualidade e quantidade da água em microbacia, afluente do rio Paraíba do Sul - São Paulo, após ações de preservação ambiental. Revista Ambiente \& Água, Taubaté, v.7, n.3, p.228-240, 2012. DOI: http://dx.doi.org/10.4136/ambi-agua.987

ALVES, E. C. R. F.; SILVINO, A. N. O.; ANDRADE, N. L. R.; SILVEIRA, A.. Gestão dos Recursos Hídricos no Estado de Mato Grosso. Revista Brasileira de Recursos Hídricos, Porto Alegre, v.14, n.3, p.69-80, 2009.

BONIFÁCIO, C. M.; FREIRE, R.. Comparação de três métodos para a medição da vazão e velocidade aplicados em dois cursos d'água da bacia do Ribeirão Maringá. Periódico eletrônico fórum ambiental da alta paulista, Tupã, v.9, n.2, 2013.

BONINI, M. A.; SATO, L. M.; BASTOS, R. G.; SOUZA, C. F.. Alterações nos atributos químico e físicos de um Latossolo Vermelho irrigado com água residuária e vinhaça. Revista Biociências, Taubaté, v.20, n.1, p.78-85, 2014.

BRASIL. Lei n. 9.433: Institui a Política Nacional de Recursos Hídricos, cria o Sistema Nacional de Gerenciamento de Recursos Hídricos. Brasília: DOU, 1997.

CAMARGO, A. P; SENTELHAS, P. C.. Avaliação do desempenho de diferentes métodos de estimativas da evapotranspiração potencial no Estado de São Paulo, Brasil. Revista Brasileira de Agrometeorologia, Santa Maria, v.5, n.1, p.89-97, 1997. 
CARVALHO, T. M.. Técnicas de medição de vazão por meios convencionais e não convencionais. Revista Brasileira de Geografia Física, Recife, v.1, n.1, p.73-85, 2008.

COAGUILA, D.; HERNANDEZ, F. B. T.; TEIXEIRA, A, H, C.. Estacionalidade da evapotranspiração e produtividade da água na Microbacia do Córrego da Mula em Santa Fé do Sul/SP. Revista Brasileira de Agricultura Irrigada, Fortaleza, v.9, n.4, p.232-238, 2015.

DALLACORT, R.; MARTINS, J. A.; INOUE, M. H.; FREITAS, P. S. L.; COLETTI, A. J.. Distribuição das chuvas no município de Tangará da Serra, médio norte do Estado de Mato Grosso, Brasil. Acta Scientiarum Agronomy, Maringá, v.33, n.2, p.193-200, 2011. DOI:

http://10.4025/actasciagron.v33i2.5838

EPA. Environmental Protection Agency. Volunteer stream monitoring: a methods manual. Washignton: United States Environmental Protection Agency, 1997.

FARIA, A. L. L.; SILVA, J. X.; GOES, M. H. B.. Análise ambiental por geoprocessamento em áreas com susceptibilidade à erosão do solo na bacia hidrográfica do ribeirão do Espírito Santo, Juiz de Fora (MG). Revista Caminhos de Geografia, v. 4, n. 9, p. 50-65, 2003.

FENNER, W.; MOREIRA, P. S. P.; FERREIRA, F. S.; DALLACORT, R.; QUEIROZ, T. M.; BENTO, T. S.. Análise do balanço hídrico mensal para regiões de transição de Cerrado-Floresta e Pantanal, Estado de Mato Grosso. Revista Acta Iguazu, Cascavel, v.3, n.1, p.72-85, 2014.

FIOREZE, A. P.; OLIVEIRA, L. F. C.; FRANCO, A. P. B.. Avaliação do desempenho de equações de regionalização de vazões na bacia hidrográfica do Ribeirão Santa Bárbara, Goiás, Brasil. Revista Ambiente e Água, Taubaté, v.3, n.2, p.62-76, 2008. DOI: $\underline{\text { http://10.4136/ambi-agua. } 53}$

GOUVEIA, R. G. L.; GALVANIN, E. A. S.; NEVES, S. M. A. S.; NEVES, R. J.. Análise da fragilidade ambiental na bacia do rio Queima-Pé, Tangará da Serra, MT. Revista Pesquisas em Geociências, v.42, n.2, p.131-140, 2015.

HORIKOSHI, A. S.; FISCH, G.. Balanço hídrico atual e simulações para cenários climáticos futuros no município de Taubaté, SP, Brasil. Revista Ambiente e Água, Taubaté, v.2, n.2, p.32-46, 2007. DOI: http://10.4136/ambi-agua. 25

LARNED, S.; DATRY, T.; ARSCOTT, D. B.; TOCKNER, K.. Emerging concepts in temporary-river ecology. Freshwater Biology, v.55, n.4, p.717-738, 2010. DOI:

http://10.1111/j.1365-2427.2009.02322.x

LEITÃO, M. M. B. R.; OLIVEIRA, G. M.; LEITÃO, T. J. V.. Avaliação do desempenho de diferentes métodos de estimativa da evaporação para duas regiões da Paraíba. Revista Brasileira de Engenharia Agrícola e Ambiental, Campina Grande, v.11, n.6, p.585-593, 2007.

LIRA, W. S.; CÂNDIDO, G. A.. Gestão sustentável dos recursos naturais: uma abordagem participativa. Campina Grande: EDUEPB, 2013.

MAROUELLI, W. A.; ABDALLA, R. P.; MADEIRA, N. R.; OLIVEIRA, A. S.; SOUZA, R. F.. Eficiência de uso da água e produção de repolho sobre diferentes quantidades de palhada em plantio direto. Revista Pesquisa Agropecuária Brasileira, Brasília, v.45, n.4, p.369-375, 2010.

MARTINS FILHO, M. V.; LICCIOTI, T. T.; PEREIRA, C. T.; MARQUES JÚNIOR, J.; SANCHEZ, R. B.. Perdas de solo e nutrientes por erosão num Argissolo com resíduos vegetais de cana-de-açúcar. Revista Engenharia Agrícola, Jaboticabal, v.29, n.1, p.8-18, 2009.

MENEZES, M. D.; CURI, N.; MARQUES, J. J.; MELLO, C. R.; ARAÚJO, A. R.. Levantamento pedológico e sistema de informações geográficas na avaliação do uso das terras em sub-bacia hidrográfica de Minas Gerais. Revista Ciência e Agrotecnologia, Lavras, v.33, n.6, p.1544-1553, 2009.

NETTO, J. M. A.; FERNANDEZ, M. F.; ARAUJO, R.; ITO, A. E.. Manual de hidráulica. São Paulo: Edgar Blücher, 1998.

OLIVEIRA, J. R.; MELO, M. T.; CASSETTARI, G. A.; QUEIROZ, T. M.. Caracterização morfométrica da Bacia Hidrográfica do Rio Branco/MT. In: JORNADA CIENTÍFICA DA UNEMAT, 8. Anais. Cuiabá, 2017.

PALHARES, J. C. P.; RAMOS, C.; KLEIN, J. B.; LIMA, J. M. M.; MULLER, S.; CESTONARO, T.. Medição da Vazão em Rios pelo Método do Flutuador. Concórdia: Embrapa Suínos e Aves, 2007

PAZ, V. P. S.; TEODORO, R. E. F.; MENDONÇA, F. C.. Recursos hídricos, agricultura irrigada e meio ambiente. Revista Brasileira de Engenharia Agrícola e Ambiental, Campina Grande, v.4, n.3, p.465-473, 2000.

PESSOA, S. P. M.; RODRIGUES, L. C.; KREITLOW, J P.; NEVES, S. M. A. S.; GALVANIN, E. A. S.; SILVA, J. S. V.; GOUVEIA, R. G. L.. Influência do uso da terra na conservação das massas d'água em sub-bacias do rio Queima-pé, Tangará da SerraMT/Brasil. In: SIMPÓSIO DE GEOTECNOLOGIAS NO PANTANAL, 4. Anais. Bonito: Embrapa Informática Agropecuária/INPE, 2012.

PINHEIRO, A.; SCHOEN, C.; SCHULTZ, J.; HEINZ, K. G. H.; PINHEIRO, I. G.; DESCHAMPS, F. C.. Relação entre o uso do solo e a qualidade da água em bacia hidrográfica rural no bioma Mata Atlântica. Revista Brasileira de Recursos Hídricos, Porto Alegre, v.19, n.3, p.127-139, 2014.

PINTO, L. V. A.; BOTELHO, S. A.; OLIVEIRA-FILHO, A. T.; DAVIDE, A. C.. Estudo da vegetação como subsídios para propostas de recuperação das nascentes da bacia hidrográfica do Ribeirão Santa Cruz, Lavras/MG. Revista Árvore, Viçosa, v.29, n.5, p.775-793, 2005.

REBOUÇAS, A. C.. Água e desenvolvimento rural. Revista Estudos Avançados, São Paulo, v. 15, n. 43, 2001.

SANTOS, I.; FILL, H. D.; SUGAI, M. R. B.; BUBA, H.; KISHI, R. T.; MARONE, E.; LAUTERT, L. F. C.. Hidrometria Aplicada. Curitiba: Instituto de Tecnologia para o Desenvolvimento, 2001.

SOUZA, A. P.; MOTA, L. L.; ZAMADEI, T.; MARTIM, C. C.; ALMEIDA, F. T.; PAULINO, J.. Classificação climática e balanço hídrico climatológico no estado de Mato Grosso. Revista Nativa, Sinop, v.1, n.1, p.34-43, 2013.

SOUZA, F. A. O.; SILVA, C. L.; MAGGIOTTO, S. R.; OLIVEIRA JÚNIOR, M. P.. Caracterização das vazões em uma pequena 
bacia hidrográfica do Distrito Federal, Brasil. Revista Brasileira de Engenharia Agrícola e Ambiental, Campina Grande, v.16, n.1, p.10-17, 2012.
WILLMOTT, C. J.; ACKLESON, S. G.; DAVIS, R. E.; FEDDEMA, J. J.; KLINK, K. M.; LEGATES, D. R.; ROWE, C. M.; O’DONNELL, J.. Statistics for the evaluation and comparison of models. Journal of Geophysical Research, Ottawa, v.90, n.C5, p.8995-9005, 1985.

A CBPC - Companhia Brasileira de Produção Científica (CNPJ: 11.221.422/0001-03) detém os direitos materiais desta publicação. Os direitos referem-se à publicação do trabalho em qualquer parte do mundo, incluindo os direitos às renovações, expansões e disseminações da contribuição, bem como outros direitos subsidiários. Todos os trabalhos publicados eletronicamente poderão posteriormente ser publicados em coletâneas impressas sob coordenação da Sustenere Publishing, da Companhia Brasileira de Produção Científica e seus parceiros autorizados. Os (as) autores (as) preservam os direitos autorais, mas não têm permissão para a publicação da contribuição em outro meio, impresso ou digital, em português ou em tradução. 